\title{
Association of recommended food score with depression, anxiety, and quality of life in Korean adults: the 2014-2015 National Fitness Award Project
}

\author{
Jo-Eun Lee ${ }^{1}$, You Jin Kim², Hee Jung Park ${ }^{3}$, Saejong Park ${ }^{4}$, Hyesook Kim² ${ }^{2 *}$ and Oran Kwon ${ }^{1,2^{*}}$
}

\begin{abstract}
Background: A healthy diet is a key determinant of an individual's health status and is closely related to mental health and quality of life (QoL); however, the exact nature of the relationship is unknown. This study hypothesized that a higher diet quality score is associated with a lower observance of symptoms of depression and anxiety and a higher QoL.

Methods: This study evaluated 1,295 adults (521 men; 774 women) aged 19-64 years, who participated in the 2014-2015 National Fitness Award Project. Diet quality was measured by the recommended food score (RFS), and mental health and QoL were assessed by the beck depression inventory (BDI), beck anxiety inventory (BAI), and the World Health Organization QoL-Brief (WHOQoL-BREF).

Results: After adjusting for covariates, the individuals with depression had a significantly lower RFS value compared to those without depression, and the group with a QoL score above the median had a higher RFS value than the group with a QoL score below the median. These trends occurred in both men and women. Subjects in the highest tertile of RFS showed a lower odds of depression (OR $=0.51,95 \% \mathrm{Cl}=0.32-0.81, p$-trend $=0.0043)$ and a QoL score below the median $(\mathrm{OR}=0.40,95 \% \mathrm{Cl}=0.30-0.54$, $p$-trend $<0.0001)$ compared with those in the lowest tertile. The RFS was not associated with anxiety.
\end{abstract}

Conclusions: Our data suggest that higher diet quality may be associated with lower depressive symptoms and a better QoL in Korean adults.

Keywords: Recommended food score: diet quality: depression: anxiety: quality of life

\section{Background}

Advances in science and technology over recent years have led to an increased life expectancy and improved living standards. As a result of this gain in life expectancy, there has been increased attention toward physical, mental, and health status, accompanied by a marked interest in the quality of life (QoL). While there is no universal consensus on the definition of QoL, the World

\footnotetext{
*Correspondence: khs7882@hanmail.net; orank@ewha.ac.kr

${ }^{2}$ Department of Nutritional Science and Food Management, Ewha Womans University, 52, Ewhayeodae-gil, Seodaemun-gu, Seoul 03760, Republic of Korea

'Department of Clinical Nutrition Science, The Graduate School of Clinical Health Sciences, Ewha Womans University, Seoul, Republic of Korea Full list of author information is available at the end of the article
}

Health Organization (WHO) defines QoL as "an individual's perception of their position in life in the context of the culture and the value system where they live, and in relation to their goals, expectations, standards and concerns" [1]. In its broadest concept, QoL encompasses physical, mental, social, and disease domains [2], and these domains are related to an increased risk of mortality [3]. The mental domain includes depression and anxiety [2], and depression and anxiety negatively influence QoL [4-6].

QoL is a relative concept that can be changed according to the degree of development of politics, the economy, society, and individual characteristics of social members, living conditions, values, and customs [7]. The

(c) The Author(s). 2019 Open Access This article is distributed under the terms of the Creative Commons Attribution 4.0 International License (http://creativecommons.org/licenses/by/4.0/), which permits unrestricted use, distribution, and reproduction in any medium, provided you give appropriate credit to the original author(s) and the source, provide a link to the Creative Commons license, and indicate if changes were made. The Creative Commons Public Domain Dedication waiver (http://creativecommons.org/publicdomain/zero/1.0/) applies to the data made available in this article, unless otherwise stated. 
pattern and extent of depression also vary considerably among individuals, owing to influences of genetic factors, gender, the social environment, and lifestyle differences [8]. Proper eating habits are key determinants of an individual's physical and mental health status and are closely related to QoL [9]. In the same regard, irregular eating habits not only hamper physical health but also affect an individual's psychological state and emotional stability [10]. Research on the association between diet and depression indicates that intakes of isolated nutrients or foods, such as omega-3 unsaturated fatty acids, folic acid, and zinc, iron or copper are involved in decreasing the risk of depression [11-15].

The limitation of focusing on the association of individual nutrients or particular food groups with diseases is the lack of consideration for the complicated interactions and cumulative effects that seem to be responsible for disease epidemics [16]. Since diet is a multidimensional exposure, it is difficult to conclude which nutrient or food is responsible for the prevalence rate of a particular disease or symptomatology [17]. Hence, in the last few years, studies have shifted toward measuring overall dietary patterns. An accumulating number of studies have shown that associations exist between overall dietary quality and depression, anxiety, or QoL, in adults in western countries [18-28]. Findings from cross-sectional investigations suggested connections between the healthy dietary pattern score [18], healthy eating index (HEI) score [19-21], and dietary diversity score [22] with depression or anxiety, and the Mediterranean diet score (MDS) with self-perceived health-related QoL (HRQoL) [23]. Cohort studies have demonstrated the influence of the MDS on mental and physical HRQoL [24], the total diet score on HRQoL [25], and the recommended food score (RFS) on HRQoL [26]. Recently, several randomized controlled trials (RCT) [27, 28] conducted in Australia indicated that a Mediterraneanstyle diet could improve mental health in adults with depression. However, the results of these investigations conducted in western populations may not apply to Korean people due to the differences in dietary habits.

Our research team previously examined the association between dietary quality and oxidative stress in the Korean population [29]. The RFS used in that study had been modified to measure the diet quality of Koreans consuming high amounts of antioxidant nutrients [29]. This same tool was used to clarify the correlation of depression with health and nutritional intake in Korean adult women aged 50-64 years, using data from the 2013 Korea National Health and Nutrition Examination Survey (KNHANES) [30]. However, the information used in that research was obtained from an unstructured questionnaire ("yes" or "no" responses to questions, such as "Do you currently have depression?") and only analyzed the unadjusted data [30]. Despite the possibility that RFS, a diet quality index that appears to be associated with lowering oxidative stress, may be related to mental health or QoL and that the expected results would aid health and nutrition promotion among people, to the best of our knowledge, no studies have investigated this association overall. Therefore, the present research reassessed the association of the RFS with depression, anxiety, and QoL in Korean adult men and women, using data sourced from structured information.

\section{Methods}

\section{Study subjects}

This study was performed within the framework of a cross-sectional survey designed to develop criteria referencing health-related fitness standards for the National Fitness Award Project [31]. The National Fitness Award project is a large-scale national project currently managed by 21 centers. The Korea Institute of Sports Science has been conducting this project since 2012, with the support of the Ministry of Culture, Sports, and Tourism to promote health by exercise, physical, and sporting activities in daily life. Adults and seniors have been recruited since 2014, and the present study was based on the 2014-2015 National Fitness Award Project for participants aged 19-64 years $(n=2,280)$. We excluded pregnant subjects $(n=1)$; those without data for the RFS $(n=973)$; those without data on the beck depression inventory (BDI), beck anxiety inventory (BAI), World Health Organization Quality of Life-Brief (WHOQoL-BREF), or all three indicators $(n=8)$; and those lacking background information, such as age, gender, and body mass index (BMI) $(n=3)$. Finally, 1,295 subjects were eligible for further analysis and stratified by gender. Ethical approval of this retrospective study was given by the Institutional Review Board (IRB) of the Korea Institute of Sport Science (KISS-201504_EFS-002-01), and Ewha Womans University (120-2, August 2018), and all subjects provided their written informed consent to participate in the study.

\section{General characteristics, socioeconomic characteristics, and} anthropometric measurements

Participants were interviewed by trained interviewers to obtain general information on demographic and socioeconomic characteristics, medical history, and health-related behaviors, including age, family income, education, marital status, smoking behavior, alcohol consumption, and menopausal state. The marital status was classified as with and without a spouse and included divorced, separated, disconnected, and single. Participants who have smoked or quit smoking within the past 12 months were considered to be smokers. Participants who consumed alcohol more than once per month were regarded as drinkers. 
Those who were diagnosed with one or more chronic diseases were considered to have chronic diseases. Physical activity was assessed through a Korean version of the International Physical Activity Questionnaire (IPAQ) short form [32]. The participants were asked to record how many hours they participated in various physical activities, and the level of physical activity was quantified as metabolic equivalent task-hours per week (MET-h/week) [33]. Standing height and body weight were measured using a stadiometer (Seca Corporation, Columbia, MD, USA) and an electronic weight scale (Inbody 720, Biospace, Seoul, Korea), respectively. BMI was computed as body weight divided by the square of the body height $\left(\mathrm{kg} / \mathrm{m}^{2}\right)$. Waist circumference was measured midway between the lowest rib and the iliac crest, using a tape measure (Tanita anthropometric tape, Seoul, Korea).

\section{Dietary assessment}

Diet quality score was assessed using the RFS developed by Kant et al. [34] to measure overall diet quality, and modified and validated by Kim et al. [29] for the reported consumption of foods based on the Korean dietary guidelines. The RFS was assessed using a questionnaire related to the previous 12 months. Forty-six foods or food groups corresponding to recommended food groups were included: grains (1), legumes (4), vegetables (17), seaweeds (2), fruits (12), fish (5), dairy products (3), nuts (1), and tea (1). The questions had structured answer choices of yes/ no to whether each food item was consumed at least once a week. The daily frequency of meals was also recorded. Participants were allocated a score of 1 if they consumed the recommended food at least weekly or ate three meals daily on a regular basis. Thus, the maximum possible score is 47 , and a higher score indicates a better diet quality.

\section{Depression assessment}

The BDI is a 21-item self-report instrument that was developed to measure symptoms of depression $[1,35]$. The current study implemented a standardized Korean version of the BDI developed by Hahn et al. [36], which contains items related to the affective, cognitive, motivational, and physiological symptoms of depression. Each item is rated by the individual on a 4-point Likert-type scale, with 0 meaning "not at all" and 3 indicating "severely," for how much the symptoms were experienced in the past week. Thus, the maximum possible score is 63 , and a high score indicates a severe depression status.

\section{Anxiety assessment}

The BAI, originally released in 1988 [37], has been regarded as one of the most popular screening and outcome research tools for measuring self-reported anxiety symptomatology [38-41]. In this study, a standardized
Korean version of the BAI, developed by Kwon et al. [42], was used. It measures 21 items on a 4-point Likerttype scale for the occurrence of sensations related to anxiety (e.g., not at all, a little, moderate, and severe), focusing both on cognitive and somatic symptoms. Thus, the maximum possible score is 63 , and a higher score indicates a severe anxiety status.

\section{QoL assessment}

QoL was assessed using the validated Korean version of the WHOQoL-BREF [43], which is a short (26-item) version of the original WHOQoL-100 questionnaire [44]. It uses a 5-point Likert scale to generate a profile and score for each of four domains: physical health (7 items), psychological health (6), social relationships (3), and environment (8). The higher scores indicate better satisfaction with life and well-being, except in regards to three negative facets, which include pain and discomfort, need for medical treatment, and negative feelings.

\section{Statistical analysis}

Participant's characteristics were shown as mean and standard deviation for continuous variables, and as numbers and percentages for categorical variables. Significant differences were evaluated between men and women, and tertiles of the RFS, respectively, using the chi-square test for categorical variables, and the Student's $t$-test for continuous variables. Pearson's correlation test was used to analyze correlations between RFS and depression, anxiety, and QoL. Multiple linear regression analysis was used to investigate the associations between the RFS and depression, anxiety, and QoL after adjusting for covariates. Subjects were dichotomized into two groups according to the presence of depression (BDI, yes: score $\geq$ 16; no: score $<16[42,45]$ ) and anxiety (BAI, yes: score $\geq$ 22; no: score $<22[37,46])$, and the WHOQOL-BREF was divided into two groups using the median (QoL score below the median: $<82$ points; QoL score above the median: $\geq 82$ points [47]) since there was no specific criterion. A general linear model was used to analyze the differences in RFS values among the two groups after adjusting for covariates. Multiple logistic regression analysis was used to estimate the adjusted odds ratios (ORs), and its corresponding 95\% confidence intervals (CIs) indicated whether the RFS was linked with depression, anxiety, and a QoL score below the median (the lowest RFS was the reference category). The covariates in this study were statistically significant in univariate analyses or were known to be factors associated with mental health or QoL in the existing literature. All analyses were adjusted for age and gender (model 1) and, additionally, for BMI, marital status, smoking, drinking, physical activity, and diagnosis of one or more chronic diseases (model 2). All statistical analyses were performed 
using IBM SPSS Statistics v.21 software. Statistical significance was set at $p<0.05$.

\section{Results}

\section{Characteristics of the participants}

Table 1 displays the characteristics of the studied subjects. The participants had a mean age of $44.0 \pm 14.5$ years, and $59.7 \%$ were women. Overall, the women had a lower BMI $\left(23.6 \pm 3.2 \mathrm{~kg} / \mathrm{m}^{2}\right)$, had attained a lower educational qualification (less than middle school 21.9\%), were married (74.7\%), had chronic diseases (24.0\%), drank alcohol less than once per month $(50.6 \%)$ and were non-smokers (99.2\%) when compared with the male subjects. The women also had a higher RFS $(p=0.0007)$, poor QoL score $(p=0.0001)$, and were less depressed (BDI; $p<0.0001$ ) and less anxious (BAI; $p<$ $0.0001)$ compared with the men.

Association of the RFS with depression, anxiety, and QoL Table 2 shows the correlation of the diet quality score (RFS) with depression (BDI), anxiety (BAI), and QoL (WHOQoL-BREF). The RFS was negatively correlated with the BDI scores and positively correlated with the WHOQoL-BREF scores. Table 3 shows the association of the diet quality score (RFS) with depression (BDI), anxiety (BAI), and QoL (WHOQoL-BREF). Overall, after adjustment for all potential confounding factors, a better diet quality (RFS) was associated with lower depression $(\beta=-0.16, p<0.0001)$ and better QoL $(\beta=0.21, p<$ 0.0001 ). The RFS had a significant positive association with physical health, psychological health, social relationship, and environment ( $p<0.0001$ for all) but it was not significantly associated with anxiety $(p=0.0898)$. The multiple linear regression analysis conducted separately by gender, showed that a healthier diet quality score (higher RFS) was associated with a lower depression score (men: $p=0.0026$, women: $p<0.0001$ ) and better QoL (men: $p=0.0001$, women: $p<0.0001$ ) in both men and women after adjustment for all potential confounding factors. However, in men, there was no significant association between a healthier diet quality score (higher RFS) and social relationships $(p=0.2678)$.

\section{RFS values of the subjects by depression, anxiety, and QoL}

Table 4 gives the adjusted mean scores for the RFS, according to the presence of depression, anxiety, and a QoL score below the median. After controlling for all covariates, participants who reported no depressive symptoms had a significantly higher diet quality score among the total subjects $(p=0.0129)$. These results show that marginally significant trends exist in the results of men $(p=0.0769)$ and women $(p=0.0788)$, respectively. However, there were no significant differences between the non-anxiety group and anxiety group ( $p=0.9376)$. The group with a QoL score above the median had a higher diet quality score than the group with a QoL score below the median after controlling for all covariates, regardless of gender $(p<0.0001$ for all).

\section{OR of depression, anxiety, and QoL according to the RFS tertiles}

The associations of the RFS with depression, anxiety, and QoL, estimated by multiple logistic regression models, are presented in Table 5. Among the total participants, diet quality score (RFS) was significantly associated with a lower risk of depression (OR per 1 score increase: 0.97; 95\% CI: 0.98-0.99) and a QoL score below the median (OR per 1 score increase: 0.96; 95\% CI: 0.94-0.97) in the fully adjusted models, respectively. There was no association between diet quality score and odds of anxiety.

In the age-adjusted models, compared to the group with the highest tertile of RFS, the OR for depression in the group with the lowest tertile was 0.31 (95\% CI: 0.13-0.73, $p$-trend 0.0042) and 0.51 (95\% CI: 0.31-0.85, p-trend $0.0093)$ for men $(n=513)$ and women $(n=752)$, respectively. Compared to the group with the highest tertile of RFS, the OR of having a QoL score below the median for the group with the lowest tertile was 0.33 (95\% CI: $0.21-$ $0.53, p$-trend < 0.0001) and 0.37 (95\% CI: 0.25-0.53, $p$-trend $<0.0001)$ for men $(n=506)$ and women $(n=751)$, respectively.

In the fully adjusted models, compared to the group with the highest tertile of RFS, the OR for depression in the group with the lowest tertile was 0.36 (95\% CI: 0.14-0.89, $p$-trend 0.0232 ) and 0.59 (95\% CI: 0.34-1.03, $p$-trend $0.0635)$ for men $(n=500)$ and women $(n=679)$, respectively. Compared to the group with the highest tertile of RFS, the OR of having a QoL score below the median for the group with the lowest tertile was 0.37 (95\% CI: $0.23-$ $0.60, p$-trend < 0.0001) and 0.42 (95\% CI: 0.28-0.63, $p$-trend $<0.0001)$ for men $(n=494)$ and women $(n=677)$, respectively.

\section{Discussion}

This study found that a higher RFS was associated with less severe depressive symptoms and a better QoL in Korean adults. These associations of RFS with depression and QoL were observed in men and women, respectively. It is the first comprehensive study to identify a positive relationship between the RFS and mental health and QoL in Korean adults [48].

There is only one previous article [30] that examined the influence of diet quality of Koreans on depression using a modified RFS, which is the same dietary quality index used in the current study. While it was found that Korean adult women aged 50-64 years with depression 
Table 1 General characteristics of the subjects according to gender

\begin{tabular}{|c|c|c|c|c|}
\hline & $\begin{array}{l}\text { Total } \\
(n=1,295)\end{array}$ & $\begin{array}{l}\text { Men } \\
(n=521)\end{array}$ & $\begin{array}{l}\text { Women } \\
(n=774)\end{array}$ & $p$-value \\
\hline Age (year) & $44.0 \pm 14.5$ & $38.5 \pm 15.1$ & $47.7 \pm 12.8$ & $<0.0001$ \\
\hline \multicolumn{5}{|l|}{ Age group } \\
\hline$<20$ & $42(3.2 \%)$ & $38(7.3 \%)$ & $4(0.5 \%)$ & \multirow[t]{5}{*}{$<0.0001$} \\
\hline $20-29$ & $248(19.2 \%)$ & 155 (29.8\%) & $93(12.0 \%)$ & \\
\hline $30-39$ & $208(16.1 \%)$ & $88(16.9 \%)$ & $120(15.5 \%)$ & \\
\hline $40-49$ & $225(17.4 \%))$ & $82(15.7 \%)$ & $143(18.5 \%)$ & \\
\hline$\geq 50$ & $572(44.2 \%)$ & $158(30.3 \%)$ & $414(53.5 \%)$ & \\
\hline Height (cm) & $163.9 \pm 9.2$ & $172.3 \pm 6.6$ & $158.2 \pm 5.7$ & $<0.0001$ \\
\hline Weight (kg) & $65.4 \pm 12.5$ & $74.7 \pm 11.7$ & $59.1 \pm 8.4$ & $<0.0001$ \\
\hline $\mathrm{BMI}\left(\mathrm{kg} / \mathrm{m}^{2}\right)$ & $24.2 \pm 3.3$ & $25.1 \pm 3.3$ & $23.6 \pm 3.2$ & $<0.0001$ \\
\hline Waist circumference (cm) & $84 \pm 9.0$ & $86.8 \pm 8.9$ & $82.1 \pm 8.6$ & $<0.0001$ \\
\hline \multicolumn{5}{|l|}{ Education } \\
\hline$\leq$ Middle school & $130(15.0 \%)$ & $27(6.8 \%)$ & $103(21.9 \%)$ & \multirow[t]{3}{*}{$<0.0001$} \\
\hline High school & $216(24.8 \%)$ & 76 (19.0\%) & $140(29.8 \%)$ & \\
\hline$\geq$ College & $524(60.2 \%)$ & $297(74.3 \%)$ & $227(48.3 \%)$ & \\
\hline \multicolumn{5}{|l|}{ Income per month (10,000won) } \\
\hline$\leq 200$ & $356(27.6 \%)$ & $111(21.4 \%)$ & $245(31.7 \%)$ & \multirow[t]{3}{*}{0.0002} \\
\hline $201-400$ & $547(42.3 \%)$ & $245(47.2 \%)$ & $302(39.1 \%)$ & \\
\hline$>400$ & 389 (30.1\%) & $163(31.4 \%)$ & $226(29.2 \%)$ & \\
\hline \multicolumn{5}{|l|}{ Marital status } \\
\hline With spouse & $852(65.8 \%)$ & $274(52.6 \%)$ & $578(74.7 \%)$ & \multirow[t]{2}{*}{$<0.0001$} \\
\hline Without spouse & $443(34.2 \%)$ & $247(47.4 \%)$ & $196(25.3 \%)$ & \\
\hline \multicolumn{5}{|l|}{ Smoking } \\
\hline Yes & $140(10.8 \%)$ & $134(25.7 \%)$ & $6(0.8 \%)$ & \multirow[t]{2}{*}{$<0.0001$} \\
\hline No & $1155(89.2 \%)$ & $387(74.3 \%)$ & $768(99.2 \%)$ & \\
\hline \multicolumn{5}{|l|}{ Alcohol drinking } \\
\hline$<1$ time/month & $462(38.4 \%)$ & $110(21.7 \%)$ & $352(50.6 \%)$ & \multirow[t]{2}{*}{$<0.0001$} \\
\hline$\geq 1$ time/month & $742(61.6 \%)$ & $398(78.3 \%)$ & $344(49.4 \%)$ & \\
\hline Physical activity (MET-hr/wk) & $16.3 \pm 16.2$ & $16.5 \pm 16.4$ & $16.2 \pm 16.2$ & 0.7378 \\
\hline \multicolumn{5}{|l|}{$\begin{array}{l}\text { Diagnosis of one or more } \\
\text { chronic disease }\end{array}$} \\
\hline Yes & $294(22.7 \%)$ & $108(20.7 \%)$ & $186(24.0 \%)$ & \multirow[t]{2}{*}{0.1490} \\
\hline No & $1001(77.3 \%)$ & $413(79.3 \%)$ & $588(76.0 \%)$ & \\
\hline \multicolumn{5}{|l|}{ Menopausal status } \\
\hline Yes & 209 (46.2\%) & - & 209 (46.2\%) & \\
\hline No & $243(53.8 \%)$ & - & $243(53.8 \%)$ & \\
\hline RFS & $25.3 \pm 9.3$ & $24.3 \pm 9.7$ & $26.1 \pm 9.0$ & 0.0007 \\
\hline $\mathrm{BDI}$ & $8.3 \pm 5.9$ & $7.3 \pm 5.6$ & $9.0 \pm 6.1$ & $<0.0001$ \\
\hline $\mathrm{BAl}$ & $6.1 \pm 6.6$ & $5.2 \pm 6.1$ & $6.8 \pm 6.9$ & $<0.0001$ \\
\hline WHOQOL & $83.0 \pm 12.2$ & $84.6 \pm 12.8$ & $81.9 \pm 11.6$ & 0.0001 \\
\hline
\end{tabular}

Abbreviations: $B M I$ body mass index, MET metabolic equivalent task, RFS recommended food score, $B D I$ beck depression inventory, $B A /$ beck anxiety inventory; WHOQOL The World Health Organization quality of life assessment

Data were available for 870 subjects for education; 1,292 subjects for income; 1,204 subjects for alcohol drinking; 452 subjects for menopausal status; 1,265 subjects for $\mathrm{BDI} ; 1,262$ subjects for $\mathrm{BAl}$; and 1,257 subjects for WHOQOL

Values are expressed as $\mathrm{N}(\%)$ or mean $\pm \mathrm{SD}$

Student's t-test or Chi-square tests for continuous and categorical variables, respectively, between men and women 
Table 2 Correlation between RFS and depression, anxiety and quality of life

\begin{tabular}{|c|c|c|c|c|c|c|}
\hline & \multicolumn{2}{|l|}{ Total } & \multicolumn{2}{|l|}{ Men } & \multicolumn{2}{|c|}{ Women } \\
\hline & $\mathrm{R}$ & $p$-value & $\mathrm{R}$ & p-value & $\mathrm{R}$ & $p$-value \\
\hline $\mathrm{BDI}$ & -0.16 & $<0.0001$ & -0.16 & 0.0003 & -0.20 & $<0.0001$ \\
\hline BAl & -0.05 & 0.7677 & -0.05 & 0.2711 & -0.07 & 0.0556 \\
\hline WHOQOL-BREF & 0.21 & $<0.0001$ & 0.20 & $<0.0001$ & 0.25 & $<0.0001$ \\
\hline \multicolumn{7}{|l|}{ WHO Domain } \\
\hline Physical health & 0.14 & $<0.0001$ & 0.14 & 0.0012 & 0.16 & $<0.0001$ \\
\hline Psychological & 0.20 & $<0.0001$ & 0.16 & $<0.0001$ & 0.23 & $<0.0001$ \\
\hline Social relationship & 0.13 & $<0.0001$ & 0.06 & 0.1736 & 0.20 & $<0.0001$ \\
\hline Environment & 0.20 & $<0.0001$ & 0.18 & $<0.0001$ & 0.23 & $<0.0001$ \\
\hline Total_WHODOM & 0.19 & $<0.0001$ & 0.17 & 0.0002 & 0.24 & $<0.0001$ \\
\hline
\end{tabular}

Abbreviations: RFS recommended food score, $B D I$ beck depression inventory, $B A$ l beck anxiety inventory; WHOQOL WHO quality of life, DOM domain Data were available for 1265 subjects (for $\mathrm{BDI}$ ); 1262 subjects (for BAl); 1257 subjects (for WHOQOL)

Table 3 Association of RFS with depression, anxiety and quality of life

\begin{tabular}{|c|c|c|c|c|c|c|c|c|c|}
\hline & \multicolumn{3}{|l|}{ Total } & \multicolumn{3}{|l|}{ Men } & \multicolumn{3}{|c|}{ Women } \\
\hline & $\bar{\beta}$ & SE & p-value & $\beta$ & SE & p-value & $\bar{\beta}$ & SE & $p$-value \\
\hline \multicolumn{10}{|l|}{$\mathrm{BDI}$} \\
\hline Model 1 & -0.19 & 0.01 & $<0.0001$ & -0.17 & 0.02 & 0.0001 & -0.21 & 0.02 & $<0.0001$ \\
\hline Model 2 & -0.16 & 0.02 & $<0.0001$ & -0.14 & 0.03 & 0.0026 & -0.18 & 0.03 & $<0.0001$ \\
\hline \multicolumn{10}{|l|}{ BAl } \\
\hline Model 1 & -0.07 & 0.02 & 0.0104 & -0.07 & 0.02 & 0.1160 & -0.07 & 0.02 & 0.0449 \\
\hline Model 2 & -0.05 & 0.02 & 0.0898 & -0.04 & 0.03 & 0.3808 & -0.06 & 0.03 & 0.1633 \\
\hline \multicolumn{10}{|c|}{ WHOQOL-BREF } \\
\hline Model 1 & 0.25 & 0.03 & $<0.0001$ & 0.22 & 0.05 & $<0.0001$ & 0.28 & 0.04 & $<0.0001$ \\
\hline Model 2 & 0.21 & 0.04 & $<0.0001$ & 0.18 & 0.06 & 0.0001 & 0.25 & 0.05 & $<0.0001$ \\
\hline \multicolumn{10}{|c|}{ WHO Domain } \\
\hline \multicolumn{10}{|c|}{ Physical health } \\
\hline Model 1 & 0.19 & 0.00 & $<0.0001$ & 0.17 & 0.01 & $<0.0001$ & 0.21 & 0.01 & $<0.0001$ \\
\hline Model 2 & 0.15 & 0.01 & $<0.0001$ & 0.14 & 0.01 & 0.0027 & 0.17 & 0.01 & $<0.0001$ \\
\hline \multicolumn{10}{|c|}{ Psychological } \\
\hline Model 1 & 0.24 & 0.00 & $<0.0001$ & 0.22 & 0.01 & $<0.0001$ & 0.25 & 0.01 & $<0.0001$ \\
\hline Model 2 & 0.20 & 0.01 & $<0.0001$ & 0.19 & 0.01 & $<0.0001$ & 0.21 & 0.01 & $<0.0001$ \\
\hline \multicolumn{10}{|c|}{ Social relationship } \\
\hline Model 1 & 0.17 & 0.00 & $<0.0001$ & 0.08 & 0.01 & 0.0475 & 0.23 & 0.00 & $<0.0001$ \\
\hline Model 2 & 0.13 & 0.01 & $<0.0001$ & 0.05 & 0.01 & 0.2678 & 0.20 & 0.01 & $<0.0001$ \\
\hline \multicolumn{10}{|c|}{ Environment } \\
\hline Model 1 & 0.25 & 0.00 & $<0.0001$ & 0.21 & 0.01 & $<0.0001$ & 0.27 & 0.00 & $<0.0001$ \\
\hline Model 2 & 0.21 & 0.01 & $<0.0001$ & 0.18 & 0.01 & 0.0001 & 0.23 & 0.01 & $<0.0001$ \\
\hline \multicolumn{10}{|c|}{ Total WHODOM } \\
\hline Model 1 & 0.24 & 0.02 & $<0.0001$ & 0.20 & 0.04 & $<0.0001$ & 0.28 & 0.03 & $<0.0001$ \\
\hline Model 2 & 0.20 & 0.03 & $<0.0001$ & 0.16 & 0.04 & 0.0005 & 0.24 & 0.03 & $<0.0001$ \\
\hline
\end{tabular}

RFS Recommended food score, $B D I$ beck depression inventory, $B A$ l beck anxiety inventory, WHOQOL The World Health Organization quality of life assessment, DOM domain

Data were available on 1,265 subjects for BDI; 1,262 subjects for BAl; and 1,257 subjects on WHOQOL

Model 1 adjusted for age

Model 2 additionally adjusted BMI, marital state, smoking, drinking, physical activity, and diagnosis of one or more chronic disease 
Table 4 RFS values of the subjects by depression, anxiety and quality of life

\begin{tabular}{|c|c|c|c|c|c|c|c|c|c|c|c|c|}
\hline & \multicolumn{4}{|l|}{ Total } & \multicolumn{4}{|c|}{ Men } & \multicolumn{4}{|c|}{ Women } \\
\hline & \multirow[t]{2}{*}{$n$} & \multirow[t]{2}{*}{ RFS values } & \multicolumn{2}{|l|}{$p$-value } & \multirow[t]{2}{*}{$n$} & \multirow[t]{2}{*}{ RFS values } & \multicolumn{2}{|l|}{$p$-value } & \multirow[t]{2}{*}{$\bar{n}$} & \multirow[t]{2}{*}{ RFS values } & \multicolumn{2}{|l|}{$p$-value } \\
\hline & & & Model 1 & Model 2 & & & Model 1 & Model 2 & & & Model 1 & Model 2 \\
\hline \multicolumn{13}{|l|}{$\overline{\mathrm{BDI}}$} \\
\hline Non-Depression & 1109 & $25.61 \pm 9.32$ & 0.0002 & 0.0129 & 468 & $24.54 \pm 9.78$ & 0.0140 & 0.0769 & 641 & $26.40 \pm 8.89$ & 0.0040 & 0.0788 \\
\hline Depression & 156 & $23.33 \pm 9.56$ & & & 45 & $21.38 \pm 8.99$ & & & 111 & $24.13 \pm 9.71$ & & \\
\hline \multicolumn{13}{|l|}{ BAI } \\
\hline Non-Anxiety & 1218 & $25.31 \pm 9.46$ & 0.7867 & 0.9376 & 501 & $24.25 \pm 9.69$ & 0.8838 & 0.6117 & 717 & $26.04 \pm 9.23$ & 0.6735 & 0.6700 \\
\hline Anxiety & 44 & $25.55 \pm 7.21$ & & & 12 & $25.33 \pm 11.45$ & & & 32 & $25.63 \pm 5.07$ & & \\
\hline \multicolumn{13}{|l|}{ WHOQOL } \\
\hline Above the median & 667 & $27.04 \pm 9.40$ & $<0.0001$ & $<0.0001$ & 295 & $26.18 \pm 9.72$ & $<0.0001$ & $<0.0001$ & 372 & $27.73 \pm 9.08$ & $<0.0001$ & $<0.0001$ \\
\hline Below the median & 590 & $23.54 \pm 8.97$ & & & 211 & $21.82 \pm 9.11$ & & & 379 & $24.50 \pm 8.76$ & & \\
\hline
\end{tabular}

RFS recommended food score, $B D I$ beck depression inventory, $B A$ l beck anxiety inventory, WHOQOL The World Health Organization quality of life assessment Subjects were dichotomized into 2 groups according to the presence of depression (BDI $\geq 16$ scores $[42,45])$ and anxiety (BAI $\geq 22$ scores [37, 46]) and the median value of WHOQOL-BREF (QoL $<82$ points [47])

Model 1 adjusted for age

Model 2 additionally adjusted BMI, marital state, smoking, drinking, physical activity, and diagnosis of one or more chronic disease

had a lower RFS than those with no depressive symptoms, the study had some limitations (an unstructured questionnaire with a mere yes or no answer to depression, and a relevance analysis that did not consider covariates at all) [30]. Applying a different RFS tool, the Australian Longitudinal Study on Women's Health (ALSWH) [49] conducted in middle-aged women investigated the relationship between an RFS for Australians and depression. After a 9-year follow-up, long-term maintenance of good diet quality was suggested to be associated with a reduced odds of depression. However, based on their 12-year follow-up study, these same researchers [50] revealed that initial associations emerged alongside baseline measures of diet quality, while depressive symptoms disappeared when methods handling time-varying covariates were applied. This suggests that residual confounding might have impacted previous studies that had established a connection between diet and depression.

As far as we know, to date, the interaction between the RFS and QoL has only been reported in the Wellbeing, Eating and Exercise for a Long Life (WELL) study conducted in Australian adults aged 55-65 years, in which adults with better quality diets reported better HRQoL, and additional associations with emotional wellbeing in women [26]. Our study and existing literature suggest a healthier diet quality is associated with improved mental health and QoL among Korean adults. However, these observational studies may have confounders, whereby subjects in better health or with a better QoL may have self-endorsed or selected to perform a physical exercise or consume nutrient-rich foods at the time of measurement. Therefore, further prospective investigations or intervention research is needed to confirm whether the association truly represents a cause-effect relationship. A recent RCT reported that application of structured dietary support, focused on elevating diet quality by using a modified Mediterranean diet model, would be more effective in reducing the severity of depressive symptomatology than would creating a social support control condition (befriending) [27]. Another recent RCT reported that a Mediterraneanstyle diet supplemented with fish oil could improve mental health in adults suffering depression [28]. In the future, more systematic RCT studies on the relationship between RFS and mental health and QoL should be conducted.

Diet quality indices can not only evaluate compliance with recommended dietary guidelines but also certain diet types, such as the Mediterranean diet [17]. Previous studies have concluded that the association between scores in diet quality (RFS and alternative-MDS) and nutrient intake are possibly explained by the guidelines and features of the Mediterranean diet, which is significantly comprised of plant foods containing potentially high amounts of active dietary antioxidants [29]. High adherence to the Mediterranean diet was considered important in improving the HRQoL, according to the Seguimiento Universidad de Navarra (SUN) cohort study [24]. Cross-sectional surveys of the Spanish adult population showed that better self-perceived mental and physical QoL were related to greater compliance with the Mediterranean diet [23].

There are many reports on dietary patterns and mental health. The consumption of a 'whole food' (heavily loaded with vegetables, fruits, and fish) pattern [51] or grains-vegetables pattern [52] was linked with a reduced risk of depressive symptoms. A pro-inflammatory diet 


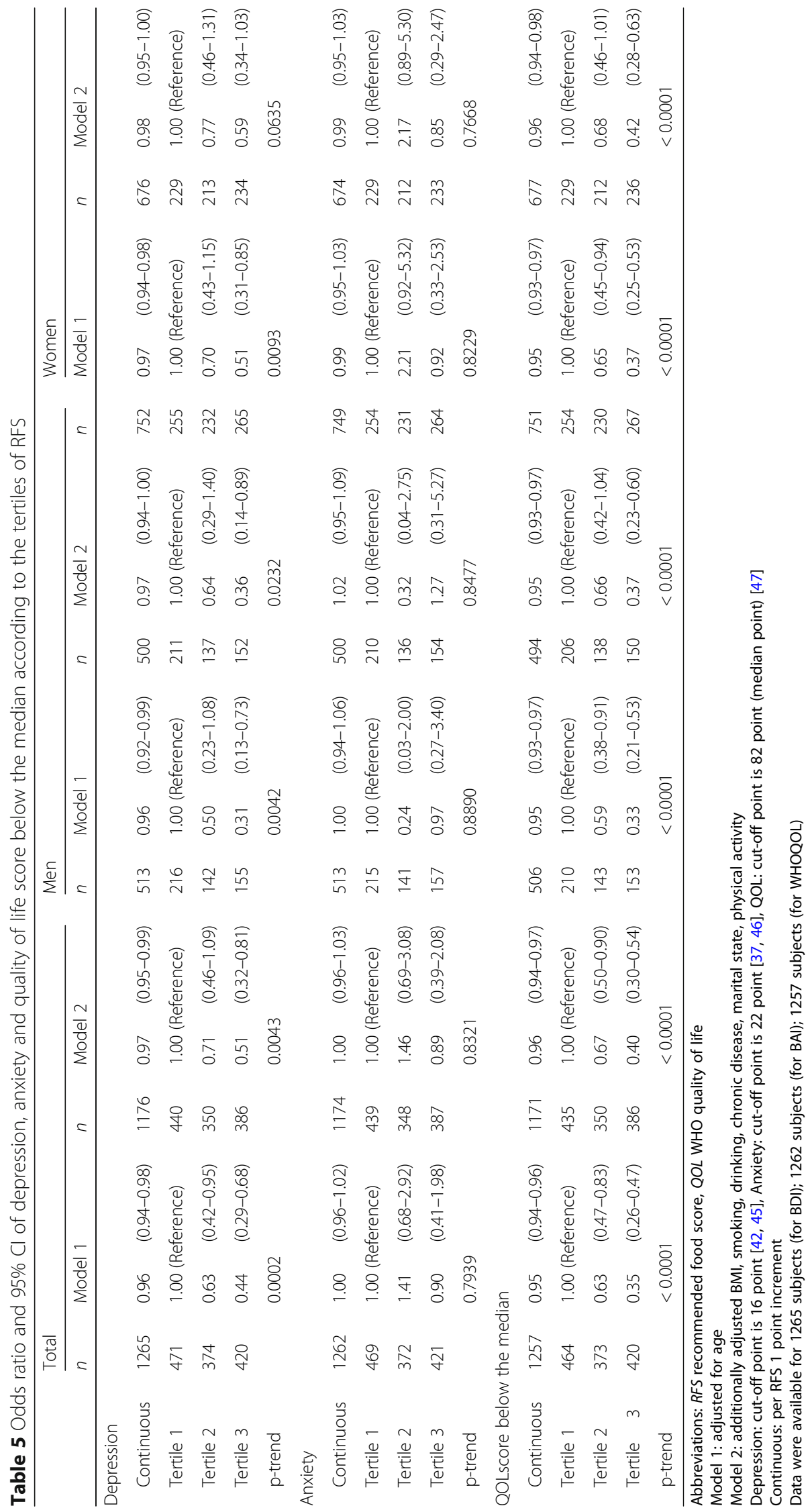


led to an increased risk of adverse mental health outcomes, including depressive symptoms, anxiety, and psychological well-being, according to a cross-sectional survey [20]. A prudent dietary pattern has been characterized by high intakes of vegetables, fruits, fish, legumes, poultry, and whole grains [53]. We expect that our findings are similar to these mentioned studies because the components of the RFS, based on the consumption of fruits, vegetables, grains, dairy products, and fish, are similar to a prudent dietary pattern.

The possible mechanisms underlying the impact of overall diet quality on mental health and QoL are explained via oxidative stress and inflammation. The diet strongly modulates genetic, immunological, biochemical, and neurodegenerative factors, and, consequently, is likely to impact on the development and occurrence of psychiatric illnesses [54]. An antioxidant-rich diet can act to slow or prevent aging-related pathophysiological and cognitive changes [55]. Inflammation can partially explain the associations with diet, medical illnesses, depression, and mortality [56-58]. The KNHANES observed that Korean elderly with a lower QoL are more likely to exhibit a lower consumption of vegetables and fruits and, thus, a lower intake of vitamins and minerals [59]. Another cross-sectional study emphasized the benefits of increasing nutrient intakes, including protein, vitamins, and minerals on HRQoL, in sarcopenic older adults [60].

The RFS is calculated based on the reported consumption of foods that contain antioxidant nutrients [29, 34], such as vitamins, selenium, and carotenoids, including $\beta$-carotene [61]. Lower diet quality may lead to inadequate antioxidant status and greater inflammation and, thus, negatively influence the pathophysiology of depressive illnesses [62] and the HRQoL [63]. Contrariwise, a better overall diet quality (higher HEI score), was shown to reduce inflammation, and improve health status, or functional outcomes affecting QoL in postmenopausal American women who survived early-stage breast cancer [64].

The current study had some limitations. First, due to the cross-sectional design, we could not confirm the causal relationship between the RFS and mental disorders or QoL. Second, only the RFS was used to assess the dietary quality, and no instruments were used for evaluating the total intake or intake of nutrients. Nevertheless, to the best of our knowledge, this study is the first to show a favorable association of the RFS with mental health and QoL in Korean adults. Spiritual wellbeing is strongly associated with all other domains of QoL (overall QoL, and mental, physical, emotional, and social well-being) [65]. Although the exact reason for the findings in this study is unclear, several explanations have been highlighted above. In any case, the current results infer the benefits of high diet quality on mental health and QoL, as investigated through standardized assessment tools for the diagnosis of depressive and anxiety disorders.

\section{Conclusions}

This study demonstrates that better diet quality is associated with lower depressive symptoms and better QoL in Korean adult men and women. More rigorous prospective studies of large cohorts or intervention studies will be needed to investigate if diet quality can influence the maintenance of mental health and QoL over time in an adult population. These findings emphasize the importance of addressing overall diet quality in future community or population-based programs or in the development of policies to prevent mood disorders and support healthy aging.

\begin{abstract}
Abbreviations
BAI: beck anxiety inventory; BDI: beck depression inventory; BMI: body mass index; HEl: healthy eating index; HRQoL: health-related quality of life; KNHANES: Korea National Health and Nutrition Examination Survey; MDS: mediterranean diet score; RCT: randomized controlled trial;

RFS: recommended food score; WHOQoL: World Health Organization quality of life
\end{abstract}

Acknowledgments

We note that we have published the abstract for our manuscript online [48].

\section{Author's contributions}

OK and HK designed the research; SP, YJK, and OK conducted the research; JEL and HK analyzed the data; JEL, YJK, HJP, and HK wrote the manuscript, and OK was primarily responsible for the final contents. All the authors read and approved the final manuscript.

\section{Funding}

This study was supported by the Bio \& Medical Technology Development Program funded by the Ministry of Science \& ICT (2012M3A9C4048761) and Future Planning through the National Research Foundation (NRF); and by RP-Grant 2018 of Ewha Womans University. The funders had no role in the study design, data collection, data analysis, data interpretation, writing of the paper, or the decision to submit the paper for publication.

\section{Availability of data and materials}

The datasets analyzed in the current study are available from the corresponding author on reasonable request.

\section{Ethics approval and consent to participate}

Study protocols and consent forms were approved by the Institutional Review Boards at the Korea Institute of Sport Science and Ewha Womans University, respectively. Written informed consent was obtained from all participants.

\section{Consent for publication}

Not applicable.

\section{Competing interests}

All authors, JE Lee, YJ Kim, HJ Park, S Park, H Kim, and K Oran, declare that they have no competing interests.

\section{Author details}

'Department of Clinical Nutrition Science, The Graduate School of Clinical Health Sciences, Ewha Womans University, Seoul, Republic of Korea.

${ }^{2}$ Department of Nutritional Science and Food Management, Ewha Womans University, 52, Ewhayeodae-gil, Seodaemun-gu, Seoul 03760, Republic of Korea. ${ }^{3}$ Department of Food and Nutrition, Yuhan University, Bucheon, 
Republic of Korea. ${ }^{4}$ Department of Sport Science, Korea Institute of Sport Science, Seoul, Republic of Korea.

\section{Received: 20 November 2018 Accepted: 10 July 2019 Published online: 17 July 2019}

\section{References}

1. The WHOQOL Group. What is quality of life? World Health Forum. 1996;17: 354-6.

2. YK O, Hwang SY. A path analysis on the effect of anxiety and depression on health-related quality of life of middle aged women. J Dig Converg. 2017; 15:579-88.

3. Van der Weele GM, Gussekloo J, De Waal MW, De Craen AJ, Van der Mast RC. Co-occurrence of depression and anxiety in elderly subjects aged 90 years and its relationship with functional status, quality of life and mortality. Int J Geriatr Psychiatr. 2009;24:595-601.

4. Sung KS. Study on relationships between depression and the quality of life (EQ-5D): centered on the subjects of survey on National Health and nutrition the fourth period the first year (2007) [master's thesis]. Seoul: Yonsei University; 2009.

5. Sivertsen H, Bjorklof GH, Engedal K, Selbaek G, Helvik AS. Depression and quality of life in older persons: a review. Dement Geriatr Cognit Disord. 2015;40:311-39.

6. Rufer M, Moergeli H, Moritz S, Drabe N, Weidt S. Alexithymia and nontreatment: an internet based study of 312 people with chronic anxiety. Compr Psychiatry. 2014:55:179-87.

7. Jung ES, Choi SK, Baek YS. Factors influencing the quality of life of community residents. J Dig Converg. 2015;13:231-9.

8. Park C, Lee J. Analysis of factors affecting the change of depression of Korean adult male and female. Health Soc Sci. 2011:29:99-128.

9. Park MS, Park K. The differences of dietary and health-related habits, depression, eating disorder and nutrient intake according to the life stress in nursing college students. JKAIS. 2014;1:344-55.

10. Park HE, Bae Y. Eating habits in accordance with the mental health status: the 5th Korea National Health and nutrition examination survey, 2010-2012. JKAIS. 2016;17:168-81.

11. Sakai H, Murakami K, Kobayashi S, Suga H, Sasaki S. Three-generations study of woman on diets and health study group. Food-based diet quality score in relation to depressive symptoms in young and middle-aged Japanese women. Br J Nutr. 2017;117:1674-81.

12. Tolmunen T, Hintikka J, Ruusunen A, Voutilainen S, Tanskanen A. Dietary folate and the risk of depression in Finnish middle-aged men. A prospective follow-up study. Psychother Psychosom. 2004;73:334-9

13. Miyake $Y$, Tanaka K, Okubo H, Sasaki S, Arakawa M. Fish and fat intake and prevalence of depressive symptoms during pregnancy in Japan: baseline data from the Kyushu Okinawa maternal and child health study. J Psychiatr Res. 2013;47:572-8.

14. Nguyen TT, Tsujiguchi H, Kambayashi Y, Hara A, Miyagi S, Yamada Y, et al. Relationship between vitamin intake and depressive symptoms in elderly Japanese individuals: differences with gender and body mass index. Nutrients. 2017;9:1319.

15. Li Z, Wang W, Xin X, Song X, Zhang D. Association of total zinc, iron, copper and selenium intakes with depression in the US adults. J Affect Disord. 2018;228:68-74

16. Hu FB. Dietary pattern analysis: a new direction in nutritional epidemiology. Curr Opin Lipidol. 2002;13:3-9.

17. Quirk SE, Williams LJ, O'Neil A, Pasco JA, Jacka FN, Housden S, et al. The association between diet quality, dietary patterns and depression in adults: a systematic review. BMC Psychiatr. 2013;13:175.

18. Jacka FN, Mykletun A, Berk M, Bjelland I, Tell GS. The association between habitual diet quality and the common mental disorders in community-dwelling adults: the Hordaland health study. Psychosom Med. 2011;73:483-90

19. Appelhans BM, Whited MC, Schneider KL, Ma Y, Oleski JL, Merriam PA, et al. Depression severity, diet quality, and physical activity in women with obesity and depression. J Acad Nutr Diet. 2012;112:693-8.

20. Kuczmarski MF, Sees AC, Hotchkiss L, Cotugna N, Evans MK, Zonderman AB. Higher healthy eating Index-2005 scores associated with reduced symptoms of depression in an urban population: findings from the healthy aging in neighborhoods of diversity across the life span (HANDLS) study. J Am Diet Assoc. 2010;110:383-9.
21. Zhijie MY, Parker L, Dummer TJB. Depressive symptoms, diet quality, physical activity, and body composition among populations in Nova Scotia, Canada: report from the Atlantic Partnership for Tomorrow's health. PrevMed. 2014;61:106-13.

22. Poorrezaeian M, Siassi F, Milajerdi A, Qorbani M, Sohrabi-Kabi R, et al. Depression is related to dietary diversity score in women: a cross-sectional study from a developing country. Ann Gen Psychiatr. 2017;16:39.

23. Muñoz MA, Fíto M, Marrugat J, Covas MI, Schröder H. Adherence to the Mediterranean diet is associated with better mental and physical health. $\mathrm{Br}$ J Nutr. 2009:101:1821-7.

24. Henríquez Sánchez P, Ruano C, de Irala J, Ruiz-Canela M, Martínez-González MA, Sánchez-Villegas A. Adherence to the Mediterranean diet and quality of life in the SUN Project. Eur J Clin Nutr. 2012;66:360-8.

25. Russell JC, Flood VM, Yeatman H, Wang JJ, Mitchell P. Food insecurity and poor diet quality are associated with reduced quality of life in older adults. Nutr Diet. 2016;73:50-8.

26. Milte CM, Thorpe MG, Crawford D, Ball K, McNaughton SA. Associations of diet quality with health-related quality of life in older Australian men and women. Exp Gerontol. 2015;64:8-16.

27. Jacka FN, O'Neil A, Opie R, Itsiopoulos C, Cotton S, Mohebbi M, et al. A randomised controlled trial of dietary improvement for adults with major depression (the 'SMILES' trial). BMC Med. 2017;15:23.

28. Parletta N, Zarnowiecki D, Cho J, Wilson A, Bogomolova S, Villani A, et al. A Mediterranean-style dietary intervention supplemented with fish oil improves diet quality and mental health in people with depression: a randomized controlled trial (HELFIMED). Nutr Neurosci. 2017:7:474-87.

29. Kim JY, Yang YJ, Yang YK, Oh SY, Hong YC, Lee EK, et al. Diet quality scores and oxidative stress in Korean adults. Eur J Clin Nutr. 2011:65:1271-8.

30. Won MS, Kim S, Yang YJ. Comparison of health status and nutrient intake between depressed women and non-depressed women: based on the 2013 Korea National Health and nutrition examination survey. Clin Nutr Res. 2016;5:112-25.

31. Kim M. National Fitness Award 100 in Korea. Korean Soc Study Phys Educ. 2014;19:75-88.

32. Oh JY, Yang YJ, Kim BS, Kang JH. Validity and reliability of Korean version of international physical activity questionnaire (IPAQ) short form. J Korean Acad Fam Med. 2007;28:532-41.

33. Committee IR. Guidelines for data processing and analysis of the International Physical Activity Questionnaire (IPAQ)-short and long forms. 2005. https://sites.google.com/site/theipaq/scoring-protocol.

34. Kant AK, Schatzkin A, Graubard BI, Schairer C. A prospective study of diet quality and mortality in women. JAMA. 2000;283:2109-15.

35. Beck AT, Ward CH, Mendelson M, Mock J, Erbaugh J. An inventory for measuring depression. Arch Gen Psychiatr. 1961;4:561-71.

36. Hahn HM, Yum TH, Shin YW, Kim KH, Yoon DJ, Chung K. A standardization study of Beck depression inventory in Korea. J Korean Neuropsychiatr Assoc. 1986:25:487-500.

37. Beck AT, Epstein N, Brown G, Steer RA. An inventory for measuring clinical anxiety: psychometric properties. J Consult Clin Psychol. 1988;56:893.

38. Kumar G, Steer RA, Beck AT. Factor structure of the Beck anxiety inventory with adolescent psychiatric inpatients. Anxiety Stress Coping. 1993:6:125-31.

39. Creamer M, Foran J, Bell R. The Beck anxiety inventory in a non-clinical sample. Behav Res Ther. 1995:33:477-85.

40. Cox BJ, Cohen E, Direnfeld DM, Swinson RP. Does the Beck anxiety inventory measure anything beyond panic attack symptoms? Behav Res Ther. 1996;34:949-54.

41. Steer RA, Ranieri WF, Beck AT, Clark DA. Further evidence for the validity of the Beck anxiety inventory with psychiatric outpatients. J Anxiety Disord. 1993;7:195-205.

42. Kwon SM, Oei TPS. Differential causal roles of dysfunctional attitudes and automatic thoughts in depression. Cognit Ther Res. 1992;16:309-28.

43. Min SK, Kim KI, Lee Cl, Jung YC, Suh SY, Kim DK. Development of the Korean versions of WHO quality of life scale and WHOQOL-BREF. Qual Life Res. 2002;11:593-600.

44. Whogol G. Development of the World Health Organization WHOQOL-BREF quality of life assessment. Psychol Med. 1998;28:551-8.

45. Lee YH, Song JY. A study of the reliability and the validity of the BDI, SDS, and MMPI-D scales, Korean J Clin Psychol. 1991:10:98-113.

46. Yook SP, Kim ZS. A clinical study on the Korean version of Beck anxiety inventory: comparative study of patient and non-patient. Korean J Clin Psychol. 1997;16:185-97. 
47. Shin MW, Ahn KS, Cho YC. Factors related to quality of life in the elderly people in long-term care centers. J Korea Acad Ind Co Soc. 2017;18:524-37.

48. Kim H, Lee JE, Park S, Kim YJ, Kwon O. Association of Recommended Food Score with Depression, Anxiety and Quality of Life in Korean Adult (P16018-19). Curr Dev Nutr. 2019;3(Suppl 1):nzz050.

49. Lai JS, Hure AJ, Oldmeadow C, McEvoy M, Byles J, Attia J. Prospective study on the association between diet quality and depression in mid-aged women over 9 years. Eur I Nutr. 2017;56:273-81.

50. Lai JS, Oldmeadow C, Hure AJ, McEvoy M, Byles J, Attia J. Longitudinal diet quality is not associated with depressive symptoms in a cohort of middleaged Australian women. Br J Nutr. 2016;115:842-50.

51. Akbaraly TN, Brunner EJ, Ferrie JE, Marmot MG, Kivimaki M, Singh-Manoux A. Dietary pattern and depressive symptoms in middle age. Br J Psychiatry. 2009;195:408-13.

52. Wang CJ, Yang TF, Wang GS, Zhao YY, Yang LJ, Bi BN. Association between dietary patterns and depressive symptoms among middle-aged adults in China in 2016-2017. Psychiatry Res. 2018;260:123-9.

53. Lopez-Garcia E, Schulze MB, Fung TT, Meigs JB, Rifai N, Manson JE, et al. Major dietary patterns are related to plasma concentrations of markers of inflammation and endothelial dysfunction. Am J Clin Nutr. 2004;80:1029-35.

54. Jacka F, Berk M. Food for thought. Acta Neuropsychiatr. 2007;19:321-3.

55. Joseph JA, Shukitt-Hale B, Denisova NA, Prior RL, Cao G, Martin A, et al. Long-term dietary strawberry, spinach, or vitamin E supplementation retards the onset of age-related neuronal signal-transduction and cognitive behavioral deficits. J Neurosci. 1998;18:8047-55.

56. Smith RS. The macrophage theory of depression. Med Hypotheses. 1991;35: 298-306.

57. Shah A, Mehta N, Reilly MP. Adipose inflammation, insulin resistance, and cardiovascular disease. J Parenter Enter Nutr. 2008;32:638-44.

58. Spranger J, Kroke A, Möhlig M, Hoffmann K, Bergmann MM, Ristow M, et al. Inflammatory cytokines and the risk to develop type 2 diabetes: results of the prospective population-based European prospective investigation into Cancer and nutrition (EPIC)-Potsdam study. Diabetes. 2003:52:812-7.

59. Kim MY. Nutrient intake and food consumption of Korean elderly aged more than 65 years according to health-related quality of life: the fourth Korea National Health and nutrition examination survey (KNHANES IV) 2007-2009 [dissertation]. Seoul: Graduate School of Chung-Ang University; 2014

60. Verlaan S, Aspray TJ, Bauer JM, Cederholm T, Hemsworth J, Hill TR, et al. Nutritional status, body composition, and quality of life in communitydwelling sarcopenic and non-sarcopenic older adults: a case-control study. Clin Nutr. 2017;36:267-74.

61. Institute of Medicine (US) Panel on Dietary Antioxidants and Related Compounds. Dietary reference intakes for vitamin C, vitamin E, selenium and carotenoids: a report of the panel on dietary antioxidants and related compounds, subcommittees on upper reference levels of nutrients and of interpretation and use of dietary reference intakes and the standing Committee on the scientific evaluation of dietary reference intakes. Washington, DC: National Academies Press; 2000.

62. Berk M, Ng F, Dean O, Dodd S, Bush Al. Glutathione: a novel treatment target in psychiatry. Trends Pharmacol Sci. 2008;29:346-51.

63. Gopinath B, Russell J, Flood VM, Burlutsky G, Mitchell P. Adherence to dietary guidelines positively affects quality of life and functional status of older adults. J Acad Nutr Diet. 2014;114:220-9.

64. Orchard TS, Andridge RR, Yee LD, Lustberg MB. Diet quality, inflammation, and quality of life in breast cancer survivors: a cross-sectional analysis of pilot study data. J Acad Nutr Diet. 2018;1 18:578-88.

65. Johnson ME, Piderman KM, Sloan JA, Huschka M, Atherton PJ, Hanson JM, et al. Measuring spiritual quality of life in patients with cancer. J Support Oncol. 2007;5:437-42.

\section{Publisher's Note}

Springer Nature remains neutral with regard to jurisdictional claims in published maps and institutional affiliations.

\section{Ready to submit your research? Choose BMC and benefit from:}

- fast, convenient online submission

- thorough peer review by experienced researchers in your field

- rapid publication on acceptance

- support for research data, including large and complex data types

- gold Open Access which fosters wider collaboration and increased citations

- maximum visibility for your research: over $100 \mathrm{M}$ website views per year

At $\mathrm{BMC}$, research is always in progress.

Learn more biomedcentral.com/submissions 